\title{
Membudayakan Bahasa Inggris Di Kampung Adat Desa Sade Lombok Tengah
}

\author{
${ }^{1}$ Agus Muliadi, ${ }^{2}$ Laras Firdaus, ${ }^{3}$ Iwan Dodi Dharmawibawa ${ }^{3}$ Fathurrahman Imran \\ ${ }^{12 \& 3}$ Prodi Pendidikan Biologi, FSTT, UNDIKMA, Jl. Pemuda No. 59A, Mataram, Indonesia \\ 83125 \\ ${ }^{4}$ Prodi Pendidikan Bahasa Inggris, FBMB, UNDIKMA, Jl. Pemuda No. 59A, Mataram, \\ Indonesia 83125
}

Email Korespondensi: larasfirdaus@ikipmatarama.ac.id

\begin{tabular}{|c|c|}
\hline Article Info & bstract \\
\hline $\begin{array}{l}\text { Article History } \\
\text { Received: } 2020-02-22 \\
\text { Revised: } 2020-02-25 \\
\text { Published: } 2020-02-31\end{array}$ & \multirow{2}{*}{$\begin{array}{l}\text { Cultivating English in the Indigenous Village of Sade Village, Central } \\
\text { Lombok. The purpose of this activity is to improve the foreign language skills } \\
\text { of tourism practitioners in Sade Traditional Village. The method of } \\
\text { implementing this program is Training and Assistance with stages, namely: site } \\
\text { survey; analysis of English language proficiency of tour operators; coordinate } \\
\text { program implementation with the Village Head and Hamlet Head; program } \\
\text { socialization; training and accompaniment of foreign languages and social } \\
\text { activities; monitoring and evaluation; closing activity. Training and mentoring } \\
\text { are carried out in stages with materials tailored to the needs of tourism actors } \\
\text { in serving tourists. In the initial and intermediate stages of training and } \\
\text { mentoring, students intensify vocabulary and speaking material and the next } \\
\text { grammer. The results of training and mentoring show a significant increase in } \\
\text { the initial stages, the tourism community can slowly memorize vocabulary. In } \\
\text { the middle stage, the tourism community has mastered vocabulary and started } \\
\text { speaking. In the final stage, this is focused on strengthening vocabulary, } \\
\text { speaking and tenses, so that the tourism community masters vocabulary and } \\
\text { speaking. Therefore, it can be concluded that training and fostering foreign } \\
\text { languages is effective in improving the vocabulary, speaking, tenses for tourism } \\
\text { actors in the Traditional Sade Village. Based on this, it is hoped that relevant } \\
\text { stakeholders in the Sade Traditional Village will hold regular foreign language } \\
\text { skills strengthening for the tourism community. }\end{array}$} \\
\hline $\begin{array}{l}\text { Keywords } \\
\text { English, } \\
\text { Village }\end{array}$ & \\
\hline Informasi Artikel & Abstrak \\
\hline $\begin{array}{l}\text { Sejarah Artikel } \\
\text { Diterima: } 22-02-2020 \\
\text { Direvisi: } 25-02-2020 \\
\text { Dipublikasi:31-02-2020 }\end{array}$ & \multirow{2}{*}{$\begin{array}{l}\text { Tujuan kegiatan ini adalah meningkatkan kemampuan bahasa asing masyarakat } \\
\text { pelaku wisata di Kampung Adat Sade. Metode pelaksanaan program ini adalah } \\
\text { Pelatihan dan Pendampingan dengan tahapan yaitu: survei lokasi; analisis } \\
\text { kemampuan bahasa inggris pelaku wisata; koordinasi pelaksanaan program } \\
\text { dengan Kepala Desa dan Kepala Dusun; sosialisasi program; pelatihan dan } \\
\text { pendampingan bahasa asing dan kegiatan sosial; monitoring dan evaluasi; } \\
\text { penutupan kegiatan. Pelatihan dan pendampingan dilaksanakan secara } \\
\text { bertahap dengan materis disesuaikan dengan kebutuhan pelaku wisata dalam } \\
\text { melayani wisatawan. Pada tahap awal dan pertengahan pelatihan dan } \\
\text { pendampingan, mahasiswa mengintensifkan materi vocabulary dan selanjutkan } \\
\text { materi speaking dan grammer. Hasil pelatihan dan pendampingan menunjukkan } \\
\text { peningkatan signifikan yaitu pada tahap awal, masyarakat pelaku wisata } \\
\text { perlahan dapat menghafal vocabulary. Pada tahap pertengahan, masyarakat } \\
\text { pelaku wisata telah menguasai vacabulary dan memulai praktik speaking. Pada } \\
\text { tahap akhir, difokuskan pada penguatan vocabulary, speaking dan disisipkan } \\
\text { tenses, sehingga masyarakat pelaku wisata menguasai vocabulary dan } \\
\text { speaking. Oleh sebab itu, dapat disimpulkan bahwa pelatihan dan pembinaan }\end{array}$} \\
\hline $\begin{array}{l}\text { Kata kunci } \\
\text { Bahasa Inggris, } \\
\text { Kampung Adat }\end{array}$ & \\
\hline
\end{tabular}


bahasa asing efektif meningkatkan kemampuan vacabulary, speaking, tenses bagi pelaku wisata Kampung Adat Sade. Berdasarkan hal ini, diharapkan stakeholder terkait di Kampung Adat Sade untuk mengadakan penguatan kemampuan bahasa asing secara reguler bagi masyarakat pelaku wisata.

Sitasi: Muliadi A., Firdaus L., Dharmawibawa d.i., Imran F. (2020) Membudayakan Bahasa Inggris Di Kampung Adat Desa Sade Lombok Tengah. Sasambo: Jurnal Abdimas (Journal of Community Service). 2(1), 28-32. Doi: 10.36312/sasambo.v2i1.184

\section{PENDAHULUAN}

Kampung Adat Sade merupakan destinasi wisata yang sudah terkenal dan banyak dikunjungi wisatawan lokal dan internasional. Kampung Adat Sade terkenal dengan budaya sasak yang masih kental baik dari bangunan rumah, cara berpakaian, aktivitas dan cara bersosialisasi masyarakatnya masih berbasis sasak tulen (asli sasak). Rumah masyarakat Kampung Adat Sade memiliki nilai estetika dan kearifan lokal serta mempertahankan tradisi nenek moyang secara turun-menurun. Rumah adat suku Sasak sangat khas karena beratap jerami, berdinding anyaman bambo, lantai terbuat dari tanah liat yang permukaannya dioleskan adonan campuran kotoran kerbau dan abu jerami, sehingga membuat lantai mengeras seperti semen (Supriati \& Hailudin, 2016).

Widianti (2017) menjelaskan bahwa Penduduk Kampung Adat Sade yang perempuan umumnya menjadi pengrajin kain sensek (tenun ikat), sedangkan yang laki-laki menjadi petani dan/atau pengrajin pernak-pernik khas suku sasak. Kain tenun tradisional dan pernakpernik khas suku sasak yang dihasilkan akan ditata rapi di teras rumah masing-masing masyarakat. Penduduk perempuan dan laki-laki biasanya dalam melayani wisatawan menggunakan pakaian khas suku Sasak. Para perempuan melaksanakan kegiatan nyensek/nenun kain khas suku Sasak di teras rumah masing-masing dengan peralatan tradisional dan sebagai salah satu daya tarik wisatawan.

Berdasarkan hasil observasi bahwa para wisatawan pengunjung Kampung Adat Sade akan disambut oleh pemandu lokal dan mengisi buku tamu serta memberikan uang sumbangan seikhlasnya sebagai dana pengembangan Kampung Adat. Wisatawan dapat berkeliling untuk mengunjungi rumah masyarakat dan menikmati pemandangan rumah khas suku Sasak dari luar maupun di dalam yang akan dipandu oleh pemilik rumah dan pemandu wisata. Setiap rumah warga, menyediakan kain sensek (tenun) dan pernak-pernik khas suku Sasak yang dapat dibeli oleh para wisatawan. Di samping itu, para wisatawan dapat pula melihat langsung ataupun mencoba peralatan tradional untuk membuat kain sensek/tenun dan dipandu langsung oleh penenunnya. Wisatawan dapat pula menikmati berbagai pagelaran adat sasak yang diselenggarakan oleh perangkat adat setempat.

Efektivitas wisata adat di Kampung Adat Sade sangat ditentukan oleh pelayanan dari pemadu lokal dan masyarakat lain (Jumadil \& Muliadi, 2016; Wijaya \& Muliadi, 2017; Wijaya \& Muliadi, 2018). Rendahnya kemampuan masyarakat dalam berbahasa inggris menjadi kendala selama ini bagi wisatawan untuk mendapatkan pelayanan yang maksimal dalam perjalanan wisata. Hal ini tentunya membuat wisatawan harus selalu ditemani oleh pemandu lokal selama berwisata adat. Namun jumlah pemandu wisata adat di Kampung Adat Sade masih rendah.

\section{METODE}

Kegiatan ini dilaksanakan dengan metode Pelatihan dan Pendampingan Lapangan dengan tahapan yaitu: (1) Survei Lokasi; (2) Observasi dan Analisis Kemampuan Bahasa Inggris Masyarakat Pelaku Wisata Kampung Adat Sade; (3) Koordinasi pelaksanaan program dengan Kepala Desa, BPD Desa dan Kepala Dusun; (4) Pelepasan mahasiswa ke Kampung Adat Sade; (5) Sosialisasi Program; (6) Kegiatan pelatihan dan pendampingan bahasa asing 
untuk pelaku wisata dan kegiatan sosial lainnya; (7) Monitoring dan Evaluasi; (8) Penutupan Kegiatan. Adapun Rincian Metode Pelaksanaan Kegiatan ini adalah sebagai berikut:

1. Observasi dan analisis rutinitas mayarakat pelaku wisata Kampung Adat Sade seperti pemandu wisata lokal, penjual souvenir, pengrajin kain tenung/sensek. Hal ini sangat diperlukan sebagian acuan penetapan teknis pelaksanaan pelatihan dan pendampingan.

2. Analisis masalah komunikasi dalam pelayanan wisata yang dilakukan oleh mayarakat pelaku wisata Kampung Adat Sade seperti pemandu wisata lokal, penjual souvenir, pengrajin kain tenung/sensek. Hal ini sangat diperlukan untuk mengetahui tingkat penguasaan awal tentang vacabulary, speaking, dan tenses, sehingga dapat dijadikan acuan untuk menyusun materi dan buku panduan praktis bahasa asing.

3. Penyusunan buku ajar praktis sebagai panduan pelatihan bahasa asing dengan materi disesuaikan dengan kebutuhan masing-masing profesi pelaku wisata yaitu pemandu wisata lokal, penjual souvenir, pengrajin kain tenung/sensek.

4. Pemetaan aktivitas pelaku wisata seperti pemandu wisata lokal, penjual souvenir, pengrajin kain tenung/sensek dalam melayani wisatawan. Hal ini sangat diperlukan untuk menyusaikan teknik pelaksanaan pelatihan dan pendampingan, sehingga tidak mengganggu profesi mereka.

5. Kegiatan pelatihan bahasa asing dilakukan tidak berkelompok, tapi dilakukan di lokasi pemandu wisata lokal, penjual souvenir, pengrajin kain tenung/sensek menjalankan aktivias melayani wisatawan, sehingga dapat langsung diberikan materi sesuai kebutuhan saat melayani. Kegiatan pelatihan dan pendampingan dilakukan selama 3 bulan.

6. Evaluasi dilakukan minima dua kali yaitu (a) Evaluasi Pertengahan untuk mengevaluasi efektivitas metode pelaksanaan kegiatan dan ketercapaian kompetensi peserta, hasil evaluasi ini dijadikan acuan untuk memperbaikan pelaksanaan pelatihan dan pendampingan lapangan selanjutannya; (a) Evaluasi Akhir untuk mengevaluasi keberhasilan program pelatihan dan pendampingan secara menyeluruh, hasil evaluasi akan digunakan sebagai dasar membuat rekomendasi kepada stakeholder terkait.

\section{HASIL DAN PEMBAHASAN}

Hasil observasi dan analisis kemampuan bahasa inggris pelaku wisata khusus pemandu wisata lokal memiliki kemampuan vocabulary dan speaking yang cukup bagus, namun masih kurang pada penguasaan tenses/grammer. Sedangkan untuk pedangan souvenir dan pengrajin kain Sensek umumnya memiliki kemampuan bahasa inggris yang sangat kurang, sehingga mereka harus didampingi oleh pemandu lokal untuk menjelaskan dan menawarkan barang dagangannya. Oleh sebab itu, penguatan kemampuan bahasa asing ini sangat diperlukan melalui pelatihan dan pendampingan di lapangan. Kegiatan pelatihan dan pendampingan dilakukan langsung pada lokasi profesi masyarakat pelaku wisata berlangsung sehari-hari. Hal ini dipertimbangkan agar tidak mengganggu pelayanan terhadap wisatawan dan pendapatan masyarakat pelaku wisata. Pelatihan diberikan dengan teknik tutorial, tanya jawab, diskusi dan didukung dengan buku pedoman belajar bahasa asing. Sedangkan pendampingan dilakukan melalui pengawasan dan pembimbingan masyarakat pelaku wisata dalam mengaplikasikan bahasa asing dalam melayani wisatawan asing secara langsung dan mandiri. Kekurangan atau kelemahan dalam proses pendampingan, akan dijadikan acuan dalam penguatan materi pelatihan selanjutnya.

Pada tahap awal, masyarakat pelaku wisata khususnya masyarakat pedagang souvenir dan pengrajin kain sensek diberikan penguatan kosa kata (vocabulary) dan speaking. Hal ini didasari atas lemahnya penguasaan vocabulary dan speaking khususnya masyarakat pedagang souvenir dan pengrajin kain sensek. Pelatihan vocabulary dan speaking yang dilakukan secara intenstif pada pertemuan awal efektif memberikan penguasaan vocabulary, walaupun tidak untuk semua peserta. Hal ini disebabkan sebagian masyarakat masih kurang 
fokus dan malu-malu dalam mengikuti materi dan kurang membaca buku pedoman. Oleh sebab itu, pada tahap selanjutnya mahasiswa mengubah teknik pelatihan agar pedagang souvenir dan pengrajin kain sensek lebih nyaman dan terbuka menerima materi. Teknik yang digunakan adalah demonstrasi yaitu tutor memberikan materi sambil memperagakan/simulasi proses transaksi/pelayanan antara penjual dan wisatawan asing. Teknik demonstrasi ini sangat efektif memberikan penguasaan peserta akan materi vocabulary dan speaking.

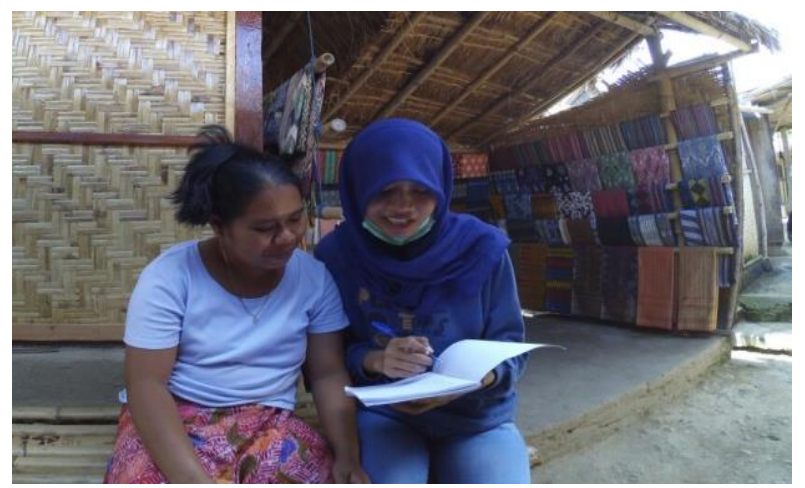

Gambar 1. Proses pelatihan bahasa inggris

Pada tahap pertengahan, tutor intensif memperdalam penguasaan vacabulary dan speaking. Tutor melatih dengan teknik demonstrasi, sehingga penguasaan vocabulary semakin bagus, namun kemampuan speaking masih kurang lancar. Hal ini disebabkan masyarakat pedagang souvenir dan pengrajin kain sensek kurang percaya diri dalam membiasakan penggunaan bahasa inggris dalam melayani wisatawan asing. Pada tahap selanjutnya, mahasiswa mengajak dan mendampingi masyarakat pedagang souvenir dan pengrajin kain sensek untuk aktif dan membiasakan diri berkomunikasi bahasa asing dalam pelayanan tamu asing.

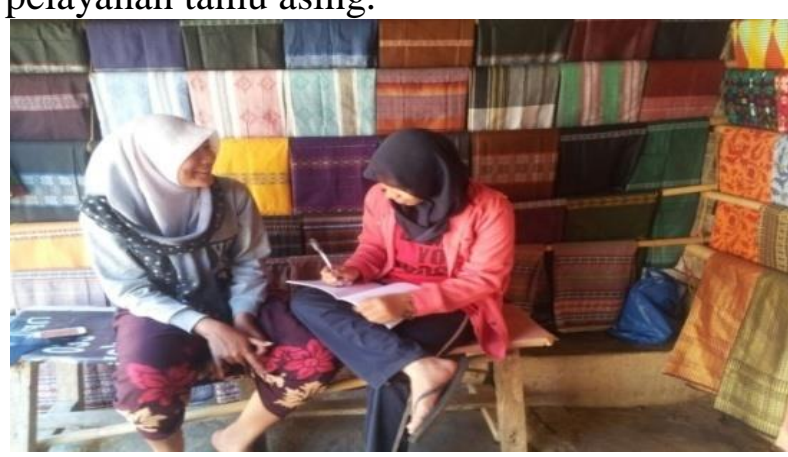

Gambar 2. Proses pelatihan bahasa inggris

Pada tahap akhir, difokuskan untuk memperkuat penguasaan vocabulary dan speaking dan disisipkan materi tenses. Pada tahan ini, tutor aktif memberikan demonstrasi penggunaan bahasa inggris dan mendampingi peserta dalam melayani wisatawan asing. Oleh sebaba itu, penguasaan vocabulary dan speaking masyarakat pelaku wisata sebagian besar sudah bagus. Namun masyarakat pelaku wisata masih kurang dalam penguasaan tenses karena mereka beranggapan bahwa yang penting wisatawan asing mengerti dengan bahasa inggris yang digunakan. Peningkatan penguasaan vocabulary dan speaking masyarakat pelaku wisata Desa Sade Lombok meningkat dan efektif digunakan dalam melayani wisatawan asing yang berkunjung di Desa Sade Lombok. 


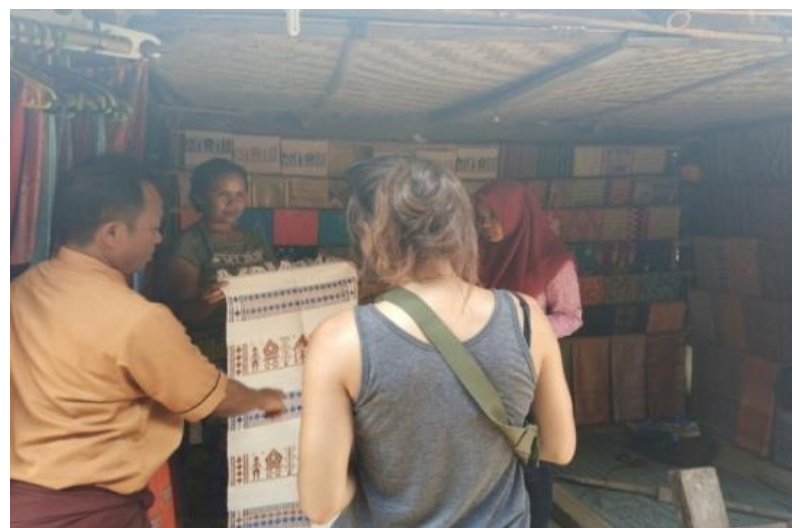

Gambar 3. Proses pendampingan pelaku wisata dalam melayani wisatawan asing

\section{KESIMPULAN}

a. Program ini dapat mengembangkan kemampuan pelaku wisata Kampung Adat Sade (pedagang souvenir, pengrajin kain sensek dan pemandu wisata lokal) dalam berbahasa inggris (Vocabulary, Tenses, dan Speaking).

b. Program ini dapat meningkatkan keterampilan pelaku wisata (pedagang souvenir, pengrajin kain sensek, pemandu wisata lokal)di Kampung Adat Sade dalam memberikan pelayanan jasa kepada wisatawan sesuai profesinya melalui kemampuan komunikasi bahasa inggris yang baik.

c. Program ini dapat meningkatkan kepuasan wisatawan asing dalam berwisata di Kampung Adat Sade karena pelaku wisata mampu berkomunikasi aktif dengannya.

d. Program ini dapat meningkatkan pendapatan pedagang souvenir karena terampil menawarkan produknya kepada wisatawan asing.

\section{UCAPAN TERIMA KASIH}

Kegiatan ini didukung oleh Kemenristekdikti dan Program Studi Pendidikan Biologi Fakultas Sains, Teknik, dan Terapan Universitas Pendidikan Mandalika, dan Fakultas Budaya Menejeman dan Bisnis Universitas Pendidikan Mandalika. Selain itu kegiatan ini didukung penuh oleh mitra.

\section{DAFTAR PUSTAKA}

Hasanah, R. (2019). Kearifan Lokal Sebagai Daya Tarik Wisata Budaya Di Desa Sade Kabupaten Lombok Tengah. DESKOVI (Art and Design Journal), Vol. 2, No. 1, 45-52.

Jumadil \& Muliadi, A. (2016). Pemberdayaan Masyarakat Daerah Wisata Gili Trawangan Lombok Berbasis CAEC (Community of Active English Communication). Jurnal Lumbung Inovasi, Vol. 1, No. 1, 7-9. http://ojs.ikipmataram.ac.id/index.php/lumbunginovasi/article/view/6

Supriati, W. \& Hailudin, H. (2016). Potensi Pengembangan Sade Sebagai Desa Wisata Lombok. Jurnal Ekonomi dan Bisnis, Vol. 20, No. 2, 69-82.

Widianti, A.K. (2017). Preservasi Rumah Adat Desa Sade Rembitan Lombok Sebagai Upaya Konservasi. VITIRUVIAN (Jurnal Arsitektur, Bangunan, \& Lingkungan), Vol. 6, No. 3, 79-84.

Wijaya, LSM. \& Muliadi A. (2017). Membangun Community of Active EnglishCommunication di Daerah Wisata Gili Air Lombok. Jurnal Lumbung Inovasi, Vol. 2, No. 1, 49-56.

http://ojs.ikipmataram.ac.id/index.php/lumbunginovasi/article/view/23

Wijaya, LSM. \& Muliadi A. (2018). Membangun Community of Active EnglishCommunication di Daerah Wisata Gili Meno Lombok. Jurnal Lumbung $\begin{array}{lllll}\text { Inovasi, } & \text { Vol. } & 3, & \text { No. } & 1,\end{array}$ http://ojs.ikipmataram.ac.id/index.php/lumbunginovasi/article/view/992 